Agron. Mesoam. 30(1):147-163. Enero-abril, 2019

ISSN 2215-3608, doi:10.15517/am.v30i1.33758

http://www.revistas.ucr.ac.cr/index.php/agromeso

\title{
Composición química y actividad antimicrobiana del aceite esencial de Psidium guajava y Cymbopogon citratus ${ }^{1}$
}

\section{Chemical composition and antimicrobial activity of the essential oil of Psidium guajava and Cymbopogon citratus}

\author{
María José Bermúdez-Vásquez², Fabio Granados-Chinchilla³, Andrea Molina
}

1 Recibido: 26 de junio, 2018. Aceptado: 10 de setiembre, 2018. Este trabajo corresponde al trabajo final de graduación de la primera autora y formó parte del proyecto de investigación B6-257 financiado por Vicerrectoría de Investigación de la Universidad de Costa Rica. San José, Costa Rica.

2 Instituto Tecnológico de Costa Rica, Escuela de Biología, Ingeniería en Biotecnología. Cartago, Costa Rica. marijo_395@hotmail.com

3 Universidad de Costa Rica, Centro de Investigación en Nutrición Animal. San José, Costa Rica. fabio.granados@ucr.ac.cr (https://orcid. org/0000-0003-4828-3727).

$4 \quad$ Universidad de Costa Rica, Escuela de Zootecnia y Centro de Investigación en Nutrición Animal. San José, Costa Rica. andrea.molina@ucr. ac.cr (autora para correspondencia; https://orcid.org/0000-0002-2852-7942).

\section{Resumen}

Introducción. La resistencia de los microorganismos a los antibióticos es un problema creciente de salud pública, que puede afectar a los productores pecuarios al contar con menos opciones para tratar a los animales ante una posible infección. Los extractos de algunas plantas con actividad antimicrobiana podrían representar una alternativa al uso de antibióticos en producción pecuaria. Objetivo. El objetivo de este trabajo fue analizar la composición química y la actividad antimicrobiana de los aceites esenciales de las hojas de guayaba (Psidium guajava L.) y de zacate de limón (Cymbopogon citratus (DC.) Stapf), cultivadas en Costa Rica, y evaluar la actividad antimicrobiana de P. guajava L. en harina de carne y hueso. Materiales y métodos. Esta investigación se desarrolló en el Centro de Investigación en Nutrición Animal (CINA) de la Universidad de Costa Rica entre marzo y octubre del 2016. Las hojas de $P$. guajava se recolectaron en las localidades de San Pedro y Escazú y las de C. citratus en Sarapiquí y Escazú, Costa Rica. La extracción de los aceites se realizó mediante hidrodestilación. La composición química se analizó mediante cromatografía de gases acoplado a un detector de espectrometría de masas. La capacidad antimicrobiana de los aceites esenciales se evaluó mediante la prueba de difusión en disco y el procedimiento de microdilución en placa de 96 pozos. Resultados. Los aceites esenciales de $C$. citratus y $P$. guajava presentaron actividad antimicrobiana contra las diez cepas bacterianas probadas, las bacterias gram positivas fueron las más sensibles a los mismos. El aceite de $P$. guajava procedente de Escazú, presentó mayor actividad antimicrobiana in vitro con respecto al proveniente de San Pedro y al aceite de $C$. citratus. El aceite de $P$. guajava eliminó Escherichia coli, que había sido previamente agregada a una matriz de harina de carne y hueso, pero no controló la colonización de la misma. Conclusión. Según los resultados obtenidos en esta investigación los aceites esenciales de zacate de Limón y de hoja de guayaba cultivadas en Costa Rica, presentan un efecto antimicrobiano contra bacterias relevantes para la inocuidad y la vida útil de alimentos para consumo animal, se requieren futuras investigaciones para evaluar su aplicabilidad en alimentación animal.

Palabras clave: aceites esenciales, antimicrobianos, guayaba, pasto Limón, piensos. 


\begin{abstract}
Introduction. The resistance of microorganisms to antibiotics is a public health problem that can affect livestock producers by having fewer options to treat animals in the event of a infection. Extracts of some plants with antimicrobial activity may represent an alternative to the use of antibiotics in livestock production. Objective. The objective of this work was to analyze the chemical composition and antimicrobial activity of the essential oils of guava leaves (Psidium guajava L.) and lemon grass (Cymbopogon citratus (DC.) Stapf) grown in Costa Rica and evaluate antimicrobial activity of $P$. guajava $\mathrm{L}$. in meat and bone meal. Materials and methods. This research was developed at the Animal Nutrition Research Center (CINA) of the University of Costa Rica between March and October 2016. P. guajava leaves were collected from two different locations (San Pedro and Escazú) and those from C. citratus from the areas of Sarapiquí and Escazú. The extraction of the oils was done by hydrodistillation. The chemical composition was analyzed by gas chromatography and mass spectrometry. The antimicrobial capacity of the essential oils was evaluated by the disk diffusion test and the 96-well plate microdilution procedure. Results. The essential oils of C. citratus and $P$. guajava presented antimicrobial activity against the ten bacterial strains tested, being the gram positive bacteria the most sensitive to them. P. guajava oil from Escazú showed higher antimicrobial activity in vitro with respect to $P$. guajava oil from San Pedro and $C$. citratus oil. The oil of $P$. guajava had the ability to eliminate Escherichia coli that had previously been added to a matrix of meat and bone meal, but not to prevent colonization of it. Conclusion. According to the results of this research, the essential oils of lemon grass and guava leaf grown in Costa Rica, have an antimicrobial effect against bacteria relevant for feed safety and feed shelf life, future research is required to evaluate its applicability in animal feed.
\end{abstract}

Keywords: essential oils, antimicrobial, guava, Lemon grass, animal feed.

\title{
Introducción
}

El descubrimiento de los antibióticos revolucionó la medicina y la calidad de vida de las personas, no obstante, la creciente resistencia microbiana a dichos antibióticos alarma los sistemas de salud, tanto humano como animal, a nivel mundial, esto debido a la creciente dificultad para tratar infecciones y al lento desarrollo de nuevas drogas, adicional el uso de antibióticos como promotores de crecimiento y salud en la alimentación animal, contribuyen al aumento en la resistencia, por lo que, se ha visto necesario recurrir a otras opciones, siendo los remedios antiguos, basados en plantas, la mejor opción (Boire et al., 2013; Granados-Chinchilla, 2017).

Las plantas producen una gran variedad de metabolitos secundarios o fitoquímicos, muchos de los cuales tienen función protectora contra predadores, contando para esto con características biocidas, antimicrobianas y/o de repelencia a herbívoros. Dentro de estos metabolitos secundarios se conocen actualmente más de 3000 aceites esenciales distintos, de estos, aproximadamente 300 son importantes a nivel comercial e industrial, debido a su sabor y fragancia, siendo utilizados principalmente en la industria de alimentos y la perfumería (Bassolé y Juliani, 2012).

Los aceites esenciales son conocidos desde épocas antiguas por su propiedad natural antimicrobiana; muchas plantas han mostrado ser efectivas en diversas aplicaciones como control del crecimiento y disminución de la sobrevivencia de microorganismos (Fischer y Phillips, 2008; Rivera et al., 2015).

Los aceites esenciales son sustancias volátiles, fragantes de consistencia aceitosa, típicamente producida por todos los órganos de las plantas, se pueden elaborar ex vitro o ser extraídos de la planta, siendo la hidrodestilación la técnica más utilizada. Generalmente, son mezclas de veinte a sesenta componentes en concentraciones diferentes, en mayor cantidad se encuentran terpenos, terpenoides y otras moléculas con anillo aromático, las cuales tienen un papel primordial en el efecto biológico antimicrobiano de estos aceites (Bakkali et al., 2008; Bassolé y Juliani, 2012; Perricone et al., 2015). 
Varios estudios indican que la actividad antimicrobiana de los aceites esenciales se debe a la inhibición o interacción de la mezcla de compuestos con múltiples blancos en la célula (Boire et al., 2013). Por ejemplo, su propiedad hidrofóbica, que resulta en la ruptura de la membrana lipídica de la membrana celular, aumentando su permeabilidad, lo que ocasiona la pérdida del contenido celular vital y su posterior muerte (Joseph y Priya, 2011).

Los microorganismos requieren de ciertas condiciones que promuevan su crecimiento y proliferación, los alimentos son fuentes ricas de nutrientes y agua, siendo el sustrato ideal para muchas especies microbianas entre ellas microorganismos responsables del deterioro de los alimentos y especies patógenas, por lo tanto, se han desarrollado agentes antimicrobianos sintéticos y preservantes químicos para los alimentos con el fin de mantener controlada la proliferación de los microorganismos (Perricone et al., 2015).

Los aceites esenciales de varias plantas han demostrado, in vitro, capacidad antimicrobiana variable contra bacterias gram positivas y gram negativas. Estos aceites también han demostrado capacidad antimicrobiana al ser adicionados a diferentes tipos de alimentos como carnes, pescado, lácteos, entre otros, aunque en cantidades mucho mayores a las utilizadas in vitro (Bassolé y Juliani, 2012), no obstante, su aplicación como preservante en la industria de alimentos puede verse limitado, ya que su actividad biológica puede ser reducida por algunos componentes de los alimentos, además el $\mathrm{pH}$, la temperatura, el tipo de procesamiento o empacado, al que son expuestos los alimentos y la flora microbiana acompañante, juegan un papel importante en la modulación del efecto antimicrobiano de estos aceites esenciales (Perricone et al., 2015).

Entre las posibles aplicaciones de los aceites esenciales estudiados está su uso en alimentos como preservantes, como tratamiento de enfermedades infecciosas humanas y animales, y como promotor del crecimiento y la salud en la producción animal para consumo humano (Rivera et al., 2015). Varios estudios señalan la capacidad antimicrobiana del zacate de limón, así como también de otras especies como la guayaba (Fischer y Phillips, 2008; Joseph y Priya, 2011).

El zacate de limón (Cymbopogon citratus (DC.) Stapf) en algunos lugares es también conocido como malojillo o pasto de limón. Este género está compuesto de aproximadamente 55 especies, y se distribuye de forma nativa en áreas del trópico y el semitrópico de Asia, y es cultivada en países tropicales. El aceite esencial extraído de la planta de zacate de limón ha sido probado en bacterias como: Bacillus subtilis, Escherichia coli, Staphylococcus aureus, Salmonella enterica serovar Paratyphi y Shigella flexneri, obteniendo resultados antibacteriales positivos, los cuales se atribuyen a tres compuestos específicos que son: el $\alpha$-citral y el $\beta$-citral que individualmente actúan sobre bacterias gram negativas y gram positivas, y el mirceno que por sí solo no presenta actividad antibacteriana apreciable (Shah et al., 2011).

La guayaba (Psidium guajava L.) es una especie que pertenece a la familia de las Myrtaceaes, ampliamente utilizada por diferentes culturas para el control de varias enfermedades como la malaria, la gastroenteritis, vómitos, diarrea, úlceras, heridas, dolores de garganta, entre otras condiciones. El aceite esencial de hoja de guayaba, se ha utilizado en la producción de perfumes, aromaterapia, cosméticos, fisioterapia y nutrición, además, se ha probado su actividad antimicrobiana en diferentes cepas de Staphylococcus aureus, Salmonella spp y Escherichia coli, mostrando una importante actividad antimicrobiana sobre las dos primeras especies, siendo su fuerte acción inhibitoria explicada por la presencia de una alta concentración de compuestos químicos activos en la planta (Joseph y Priya, 2011).

Existen diferentes métodos para probar la actividad antimicrobiana de extractos botánicos incluyendo aceites esenciales, estos se pueden agrupar en tres clases: difusión, dilución o métodos auxográficos. Entre los procedimientos análiticos más utilizados en aceites esenciales están: concentración mínima inhibitoria (MIC), concentración mínima bactericida (MBC), concentración bacteriostática y concentración bactericida (Perricone et al., 2015). La escogencia del método analítico va a depender de las características químicas y físicas del extracto a evaluar y del uso final que se quiere dar a dicho extracto, por ejemplo, como bacteriostático o bactericida.

El objetivo de este trabajo fue analizar la composición química y la actividad antimicrobiana de los aceites esenciales de las hojas de guayaba ( $P$. guajava) y de zacate de limón (C. citratus), cultivadas en Costa Rica, y evaluar la actividad antimicrobiana en harina de carne y hueso usada para alimentación animal de $P$. guajava. 


\section{Materiales y métodos}

\section{Localización y periodo experimental}

Este estudio se llevó a cabo en el laboratorio de Microbiología del Centro de Investigación en Nutrición Animal (CINA), Universidad de Costa Rica, durante los meses de marzo a octubre de 2016.

\section{Material vegetal}

Las hojas de guayaba silvestre (Psidium guajava L.) (fruto con pulpa rosada) se recolectaron de la provincia de San José en los cantones de Montes de Oca (09 56'11" N 8402'43" O, altitud 1210 msnm. Condiciones de temperatura, humedad relativa y precipitación promedio de $25,3{ }^{\circ} \mathrm{C}, 61 \%$ y $8,4 \mathrm{~mm}$, respectivamente) y Escazú (0953'24" N 84¹1'22" O, altitud $1717 \mathrm{msnm}$. Condiciones de temperatura, humedad relativa y precipitación promedio de $23,1^{\circ} \mathrm{C}, 71 \%$ y $35,8 \mathrm{~mm}$, respectivamente). El zacate de limón (Cymbopogon citratus (DC.) Stapf), fue recolectado en la provincia de San José, cantón de Escazú y en la provincia de Heredia, cantón de Sarapiquí $\left(10^{\circ} 25^{\prime} 53,14^{\prime \prime} \mathrm{N} 84^{\circ} 00^{\prime} 10,51^{\prime \prime} \mathrm{O}\right.$, altitud $37 \mathrm{msnm}$. Condiciones de temperatura, humedad relativa y precipitación promedio de $30,4{ }^{\circ} \mathrm{C}, 68 \%$ y $16,8 \mathrm{~mm}$, respectivamente). Se seleccionaron dos localidades distintas con el fin de evaluar si la composición química y la actividad antimicrobiana variaban dependiendo de la posición geográfica. Se escogieron zonas donde se tenía acceso al material vegetal requerido para esta investigación. Para ambas especies se eligieron hojas sanas, sin importar su estadio de desarrollo. Se lavaron con agua destilada y se cortaron en trozos de aproximadamente $1 \mathrm{~cm}$ de longitud. Se mantuvieron en refrigeración $\left(4^{\circ} \mathrm{C}\right)$ hasta ser utilizadas.

\section{Extracción aceites esenciales}

Para la extracción de los aceites esenciales se utilizó la metodología previamente descrita en GranadosChinchilla et al. (2016), que se basa en la técnica de hidrodestilación (Granados-Chinchilla et al., 2016). Se prepararon balones aforados con $75 \mathrm{~g}$ de material vegetal. La destilación duró tres horas y media, a una temperatura de $100{ }^{\circ} \mathrm{C}$, y se mantuvo constante el volumen del balón en aproximadamente $400 \mathrm{ml}$ de agua destilada. En campana de gases, se realizó la separación de fases del destilado, con fracciones de $50 \mathrm{ml}$ de líquido, y como disolvente orgánico éter etílico. Se dejó evaporar el éter, para así recuperar únicamente el aceite esencial de las plantas, posteriormente, se pesó para obtener un rendimiento de extracción. La cantidad de material vegetal inicial utilizado para la extracción de aceites esenciales fue de 1125,450, 1605 y 105 g para el zacate de limón de Escazú y de Sarapiquí, hoja de guayaba de Escazú y de San Pedro, respectivamente.

\section{Determinación de la composición química de los aceites esenciales}

La composición química se analizó mediante cromatografía de gases y espectrometría de masas, con base en la metodología previamente descrita en Granados-Chinchilla et al. (2016). Se empleó de una dilución 1:25 con éter etílico, y el análisis de los cromatogramas con los programas MassHunter Unknown Analysis verisón B.07.00 y Qualitative Analysis versión B.06.00 SP1 (Agilent Technologies). Los constituyentes se identificaron mediante la comparación del espectro con los de la librería NIST 14, solo se consideraron las coincidencias que tuvieran un factor de concordancia mayor al 80\%, en todos los casos se utilizó geraniol (98\% de pureza) como estándar interno. Los analitos con composición relativa $\geq 5 \%$, fueron monitoreados simultáneamente con la modalidad SIM (selected-ion monitoring) para confirmar la identidad de los compuestos. 


\section{Cepas bacterianas}

Se trabajó con las siguientes cepas bacterianas, Escherichia coli (ATCC 25922), E. coli O157:H7 (ATCC 43888), Staphylococcus aureus (ATCC 25923), Salmonella enterica serovar Typhimurium (ATCC 14028), S. enterica serovar Enteritidis (ATCC 13076), S. enterica serovar Choleraesuis (ATCC 10708) Bacillus cereus (ATCC 13061), B. subtilis (ATCC 11774), Pseudomona aeruginosa (ATCC 27853) y Proteus mirabilis (ATCC 25933). Se subcultivaron en agar Standard, y se incubaron a $35^{\circ} \mathrm{C}$ por $24 \mathrm{~h}$ previo a los ensayos; para su uso, se elaboraron diluciones McFarland 0,5, la concentración se corroboró y ajustó utilizando un espectrofotómetro, una absorbancia entre 0,08-0,12 a $625 \mathrm{~nm}$ que corresponde a $10^{8} \mathrm{UFC} / \mathrm{ml}$ (Balouiri et al., 2016). Se utilizó caldo Mueller Hinton ajustado con cationes para trabajar con las bacterias; no obstante, S. aureus utiliza una variación, a dicho caldo se le agrega $20 \% \mathrm{NaCl}$, al considerarse una bacteria halofílica (CLSI, 2012).

\section{Prueba de difusión con disco y determinación del porcentaje de inhibición del crecimiento microbiano}

Se realizó el procedimiento de difusión con disco, tal como lo indican Jorgensen y Ferraro (2009), en el cual se utilizaron los cuatro aceites esenciales en una dilución 8:2 con dimetilsulfóxido (DMSO), un control positivo con tetraciclina $(30 \mu \mathrm{g} / \mathrm{ml})$ y un control negativo con DMSO. El procedimiento consiste en inocular uniformemente, con la bacteria de interés, la superficie de una placa de agar; colocar sobre la superficie del agar un disco de papel filtro (de aproximadamente $6 \mathrm{~mm}$ ) que contenga el agente antimicrobiano en la concentración deseada e incubar bajo las condiciones idóneas requeridas por las bacterias utilizadas. Los agentes antimicrobianos se difunden en el agar e inhiben la germinación formando halos donde no hay crecimiento bacteriano visible, el diámetro de los halos de inhibición es relativo a la susceptibilidad del microorganismo al antimicrobiano probado.

Con base en el diámetro de los halos, se utilizó la siguiente fórmula para obtener el efecto de inhibición de cada aceite con respecto al halo generado por el antibiótico (Martínez et al., 1997):

$$
\text { Porcentaje de efecto de inhibición }=\frac{\text { Diámetro halo de inhibición del aceite }(\mathrm{mm})}{\text { Diámetro halo de inhibición control positivo }(\mathrm{mm})}
$$

\section{Determinación de la concentración mínima inhibitoria (MIC)}

La determinación de la concentración mínima inhibitoria (MIC), que corresponde a la concentración más baja del agente antimicrobiano probado que sea capaz de inhibir el crecimiento de los microorganismos de forma visible, se obtuvo con base en el procedimiento de microdilución en placa de 96 pozos, como lo indica Balouiri et al. (2016). Este procedimiento involucró la elaboración de diluciones seriadas dobles de los aceites esenciales a probar en DMSO. Estas diluciones se dispersaron en placas de 96 pozos, posteriormente, se inocularon con una dilución bacteriana ajustada a un McFarland 0,5 , y se incubaron 48 h a $35^{\circ} \mathrm{C}$. La resazurina se usó como indicador de viabilidad de las bacterias probadas; la resazurina (azul) es reducida a resorufina (rojo) por óxido reductasas que se encuentran principalmente en la mitocondria de células vivas. Luego de la incubación, por observación visual, se determinó la MIC, que correspondió a la dilución menos concentrada del aceite esencial que presentaba color azul, para cada bacteria con cada aceite esencial probado. El control negativo contenía $50 \mu 1$ de antibiótico (Tetraciclina $30 \mu \mathrm{g} / \mathrm{ml}$ ), $50 \mu \mathrm{l}$ de caldo Mueller Hinton ajustado con cationes y $10 \mu 1$ de resazurina $0,01 \mathrm{~g} / 100 \mathrm{ml}$. El control positivo contenía $10 \mu 1$ DMSO, $40 \mu 1$ caldo Mueller Hinton ajustado con cationes, $50 \mu 1$ dilución bacteriana y 10 $\mu 1$ de resazurina. 


\section{Determinación de la concentración bactericida inhibitoria (MBC)}

La determinación de la concentración bactericida inhibitoria (MBC), se efectuó una vez conocido el valor de la MIC en cada bacteria para los cuatro aceites. Luego de la lectura visual de la MIC, se tomaron $10 \mu 1$ del pozo designado como la mínima concentración inhibitoria, o $10 \mu 1$ del pozo anterior (correspondiente al doble de la concentración designada como MIC), o $10 \mu \mathrm{l}$ del pozo posterior (correspondiente a la mitad de la concentración designada como MIC), y se cultivaron en placas de agar Mueller Hinton. Se dejaron incubando por $24 \mathrm{~h}$ a $35^{\circ} \mathrm{C}$. Luego de la incubación se revisaron las placas en busca de unidades formadoras de colonias (UFC) bacterianas. La concentración bactericida inhibitoria se tomó como aquella en la cual no hubo crecimiento bacteriano visible en las placas de agar.

\section{Obtención de extractos adicionales}

A partir de las hojas de guayaba de Escazú se elaboraron cuatro extractos botánicos adicionales, se eligió este material vegetal ya que fue el que presentó la mayor actividad antibacteriana en la prueba MIC. Uno de los extractos se obtuvo mediante la técnica de infusión, se pesaron $150 \mathrm{~g}$ de material vegetal, el cual se encontraba en pequeños trozos, y se le agregó $300 \mathrm{ml}$ de agua hirviendo, se dejó reposar por 15 min y posteriormente se filtró.

Los siguientes tres extractos se obtuvieron mediante una maceración con tres disolventes diferentes, basado en el trabajo de Jahani et al. (2016), con algunas modificaciones, se pesaron $10 \mathrm{~g}$ de material vegetal y se dejaron reposar por $48 \mathrm{~h}$ con $30 \mathrm{ml}$ de etanol o metanol o acetona-agua (80:20), posteriormente, se filtraron y se dejó evaporar el disolvente. Se realizó una prueba de difusión en disco para los cuatro extractos, con Escherichia coli y Salmonella enterica serovar Typhimurium.

\section{Ensayo en harina de carne y hueso}

Se colocaron $400 \mathrm{~g}$ de harina de carne y hueso en un autoclave por un periodo de $15 \mathrm{~min}$ a $121{ }^{\circ} \mathrm{C}$. Posteriormente, y de forma aséptica, se prepararon bolsas de ensayo estériles con $25 \mathrm{~g}$ de la harina. Ensayo 1: A los $25 \mathrm{~g}$ de harina de carne y hueso estéril se le agregaron $10 \mathrm{ml}$ de una disolución 1:80 de aceite esencial de hojas de guayaba (Psidium guajava) en agua destilada y se dejó reposar a temperatura ambiente durante 1 h, luego se inoculó con E. coli o con S. enterica serovar Typhimurium. Ensayo 2: Se inoculó con E. coli o con S. enterica serovar Typhimurium los $25 \mathrm{~g}$ de harina de carne y hueso estéril y se dejó reposar a temperatura ambiente durante $1 \mathrm{~h}$, luego se le agregaron $10 \mathrm{ml}$ de una disolución 1:80 de aceite esencial de hojas de guayaba (P. guajava) en agua destilada.

Los ensayos se efectuaron por duplicado. Se realizaron pruebas para cuantificar E. coli y determinar presencia o ausencia de $S$. enterica serovar Typhimurium, en el tiempo 0 y pasados 7 días de incubación a temperatura ambiente. Los análisis de E. coli y Salmonella se ejecutaron siguiendo los métodos establecidos y acreditados (según norma INTE/ISO/IEC 17025) en el laboratorio de microbiología del CINA (Molina et al., 2016), los cuales están basados en los ensayos AOAC 967.25/967.28/994.04/978.24 y métodos 9.91-9.94 de la APHA/CMMEF (basados en la técnica de número más probable) y 34.22-34.24. Para corroborar los resultados, se repitieron los ensayos que daban resultados positivos de inhibición bacteriana, de la misma forma expuesta anteriormente.

\section{Análisis estadístico}

Se realizó un análisis de varianza con una prueba pos hoc de Tukey para comparar el porcentaje de inhibición de los cuatro aceites evaluados considerando la localidad. El mismo se llevó a cabo con base en el programa IBM PAWS Statistics 22 (SPSS, Inc., Armonk, NY). $P<0,05$ se usó como el punto de corte para la diferencia significativa. 


\section{Resultados}

\section{Extracción de aceites esenciales}

El porcentaje de recuperación (la cantidad total (g) de material vegetal utilizado por planta/la cantidad total de aceite extraído de cada planta) fue menor al $1 \mathrm{~g}$ aceite/100 g material vegetal en los cuatro aceites preparados (Figura 1).

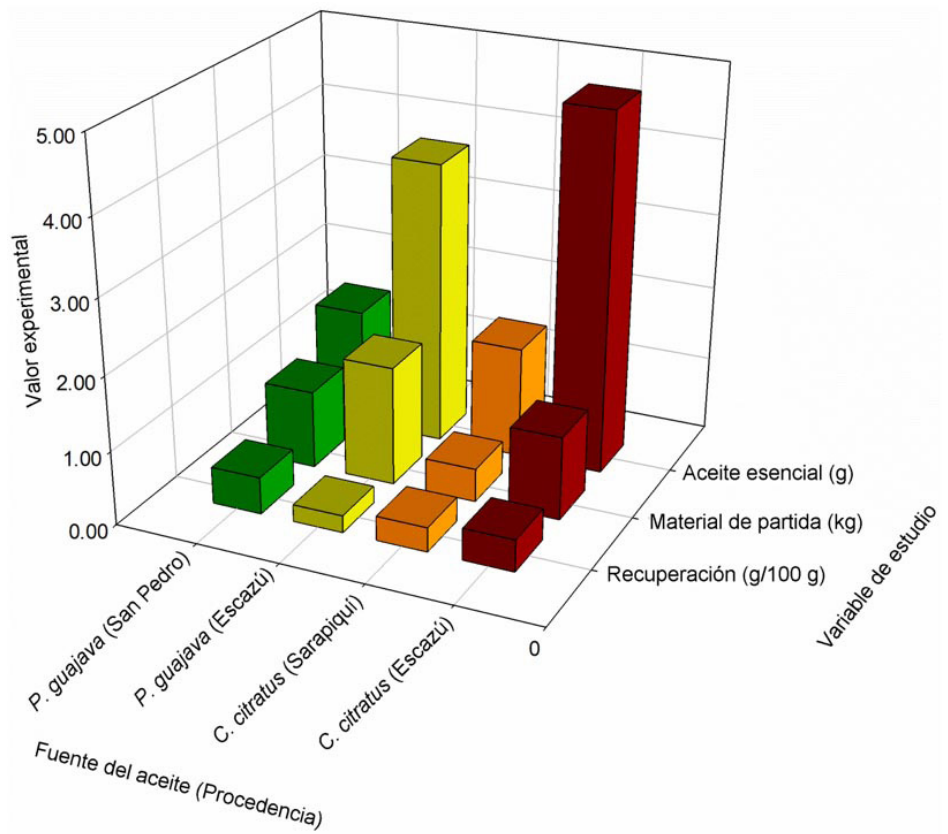

Figura 1. Recuperación de aceite esencial a partir de Cymbopogon citratus de Escazú y Sarapiquí y a partir de hoja de Psidium guajava de Escazú y San Pedro, San José, Costa Rica. Centro de Investigación en Nutrición Animal (CINA), Universidad de Costa Rica. 2016.

Figure 1. Recovery of essential oil from Cymbopogon citratus from Escazú and Sarapiquí and from Psidium guajava leaf from Escazú and San Pedro, San José, Costa Rica. Centro de Investigación en Nutrición Animal (CINA), Universidad de Costa Rica. 2016.

El zacate de limón, de ambas localidades, presentó mejores rendimientos de recuperación que la hoja de guayaba, siendo el zacate de limón de Escazú el más eficiente, mientras que la hoja de guayaba de San Pedro la menos eficiente de las cuatro (Figura 1).

\section{Composición química de los aceites esenciales}

En el análisis de la composición química del aceite esencial de zacate de limón proveniente de Escazú y el de Sarapiquí, algunos de los compuestos no fueron detectados en ambas localidades, como es el caso del mirceno, limoneno, geraniol y 2,4-di-tert-butilfenol. Solo cuatro compuestos se encontraron en ambos aceites, y fue Sarapiquí, la localidad donde tres de ellos se encontraron en mayor concentración (Cuadro 1). El $\beta$-citral y $\alpha$-citral fueron los compuestos predominantes en ambas localidades (Cuadro 1). 
Cuadro 1. Valor porcentual de compuestos presentes en los aceites de Cymbopogon citratus de Escazú y Sarapiquí y los aceites de hojas de Psidium guajava de Escazú y San Pedro. Centro de Investigación en Nutrición Animal (CINA), Universidad de Costa Rica. San José, Costa Rica. 2016.

Table 1. Percentile values of compounds present in the essential oils of Cymbopogon citratus from Escazú and Sarapiquí and Psidium guajava leaves from Escazú and San Pedro. Centro de Investigación en Nutrición Animal (CINA), Universidad de Costa Rica. San José, Costa Rica. 2016.

\begin{tabular}{lcc}
\hline Compuesto & \multicolumn{2}{c}{ Suma relativa de áreas, g/100 g } \\
\hline & \multicolumn{2}{c}{ Cymbopogon citratus } \\
\cline { 2 - 3 } Mirceno & Escazú & Sarapiquí \\
Limoneno & & 9,18 \\
Isoneral & & 2,47 \\
Isogeranial & 0,72 & 3,97 \\
$\boldsymbol{\beta}$-citral & 1,56 & 3,88 \\
$\boldsymbol{\alpha}$-citral & $\mathbf{3 0 , 6 7}$ & $\mathbf{3 3 , 0 1}$ \\
Geraniol & $\mathbf{4 9 , 6 1}$ & $\mathbf{3 7 , 5 1}$ \\
2,4-di-tert-butilfenol & & 4,28 \\
Ácido geránico & & 5,7 \\
Ácido 3,5-di-tert-butil-4-hidroxifenilpropiónico & 14,43 & \\
& 3,01 & \\
& & Psidium guajava \\
Limoneno & Escazú & San Pedro \\
Eucaliptol & 3,06 & 3,22 \\
Cariofileno & 3,37 & 1,17 \\
$\alpha$-selineno & 10,74 & 18,62 \\
Óxido de cariofileno & 36,15 & 30,67 \\
1-nonadeceno & 8,3 & \\
Neointermediol & & 20,84 \\
$\alpha$-cardinol & 3,77 & 2,66 \\
2,4-di-tert-butilfenol & 2,23 & $\mathbf{7 , 5 3}$ \\
Cariofila-4(12),8(13)-dien-5 $\alpha$-ol & $\mathbf{3 0 , 5 6}$ & 4,89 \\
1-octadecanol & & 2,46 \\
\hline
\end{tabular}

Los compuestos que conformaron el aceite esencial de hoja de guayaba para ambas localidades se indican en el Cuadro 1. En este caso hubo mayor cantidad de compuestos, y mayor número de coincidencias entre aceites, además, se aprecia que el aceite de la zona de San Pedro $(n=8)$ presentó un compuesto más que el de la zona de Escazú $(n=9)$. El aceite esencial de hojas de guayaba de ambas localidades, estuvo principalmente compuesto por sesquiterpenos como el cariofileno y el selineno. El 2,4-di-tert-butilfenol estuvo presente en mayor proporción en el aceite de guayaba proveniente de Escazú (Cuadro 1).

\section{Prueba de difusión con disco}

El aceite extraído de las hojas de zacate de limón de ambas localidades presentó actividad antimicrobiana contra todas las bacterias probadas, en la mayoría de bacterias, su efecto de inhibición sobrepasó el 50\% (Cuadro 2). El material que provenía de la zona de Sarapiquí presentó diámetros de inhibición más grandes que los del material de Escazú. En géneros como Escherichia se observó un efecto de inhibición superior al 50\%, en Salmonella el efecto inhibitorio del aceite de zacate de limón fue de 26,7-36,7\% (Figura 2 y 3). 
Cuadro 2. Determinación de actividad inhibitoria de los aceites esenciales en Cymbopogon citratus y Psidium guajava, y cálculo de la concentración mínima inhibitoria (MIC) y mínima bactericida (MBC). Centro de Investigación en Nutrición Animal (CINA), Universidad de Costa Rica. San José, Costa Rica. 2016.

Table 2. Determination of inhibitory activity of Cymbopogon citratus and Psidium guajava essential oils and calculation of the minimum inhibitory concentration (MIC) and minimum bactericidal concentration (MBC). Centro de Investigación en Nutrición Animal (CINA), Universidad de Costa Rica. San José, Costa Rica. 2016.

\begin{tabular}{|c|c|c|c|c|c|c|c|c|c|}
\hline \multirow[t]{3}{*}{ Microorganismo } & \multicolumn{4}{|c|}{ Zacate de limón } & \multicolumn{4}{|c|}{ Hojas de guayaba } & \multirow{3}{*}{\begin{tabular}{|c|}
$\begin{array}{c}\text { Control } \\
\text { positivo }\end{array}$ \\
$\begin{array}{c}\text { Tetraciclina } \\
(30 \mu \mathrm{g})\end{array}$ \\
$\begin{array}{c}\text { Diámetro } \\
(\mathrm{mm})\end{array}$
\end{tabular}} \\
\hline & \multicolumn{2}{|c|}{ Escazú $^{a}$} & \multicolumn{2}{|c|}{ Sarapiquía $^{a}$} & \multicolumn{2}{|c|}{ Escazúa $^{a}$} & \multicolumn{2}{|c|}{ San Pedro $^{\mathrm{b}}$} & \\
\hline & $\begin{array}{l}\text { Diámetro } \\
(\mathrm{mm})\end{array}$ & $\begin{array}{c}\text { Inhibición } \\
(\%)\end{array}$ & $\begin{array}{l}\text { Diámetro } \\
(\mathbf{m m})\end{array}$ & $\begin{array}{c}\text { Inhibición } \\
(\%)\end{array}$ & $\begin{array}{l}\text { Diámetro } \\
(\mathrm{mm})\end{array}$ & $\begin{array}{c}\text { Inhibición } \\
(\%)\end{array}$ & $\begin{array}{l}\text { Diámetro } \\
\text { (mm) }\end{array}$ & $\begin{array}{c}\text { Inhibición } \\
(\%)\end{array}$ & \\
\hline Escherichia coli & 12 & 54,55 & 17 & 77,27 & 14 & 63,64 & 0 & 0 & 22 \\
\hline $\begin{array}{l}\text { Escherichia coli } \\
\text { O157:H7 }\end{array}$ & 19 & 59,38 & 16 & 50,00 & 39 & $>100$ & 0 & 0 & 32 \\
\hline $\begin{array}{l}\text { Staphylococcus } \\
\text { aureus }\end{array}$ & 30 & 93,75 & 32 & 100 & 31 & 96,88 & 18 & 56,25 & 32 \\
\hline $\begin{array}{l}\text { Salmonella } \\
\text { Typhimurium }\end{array}$ & 8 & 26,67 & 11 & 36,67 & 14 & 46,67 & 0 & 0 & 30 \\
\hline $\begin{array}{l}\text { Salmonella } \\
\text { Enteritidis }\end{array}$ & 12 & 40,00 & 14 & 46,67 & 36 & $>100$ & 0 & 0 & 30 \\
\hline $\begin{array}{l}\text { Salmonella } \\
\text { Cholerasuis }\end{array}$ & 11 & 50,00 & 11 & 50,00 & 31 & $>100$ & 0 & 0 & 22 \\
\hline Bacillus cereus & 20 & 58,82 & 63 & $>100$ & 11 & 32,35 & 9 & 26,47 & 34 \\
\hline Bacillus subtilis & 47 & $>100$ & 39 & $>100$ & 30 & $>100$ & 17 & $>100$ & 8 \\
\hline $\begin{array}{l}\text { Pseudomonas } \\
\text { aeruginosa }\end{array}$ & 7 & 70,00 & 8 & 80,00 & 16 & $>100$ & 9 & 90,00 & 10 \\
\hline Proteus mirabilis & 11 & $>100$ & 23 & $>100$ & 30 & $>100$ & 8 & 80,00 & 10 \\
\hline & MIC & $\mathrm{MBC}$ & MIC & $\mathrm{MBC}$ & MIC & MBC & MIC & $\mathrm{MBC}$ & \\
\hline Escherichia coli & $1: 80$ & $1: 80$ & $1: 40$ & $1: 20$ & $1: 160$ & $1: 320$ & $1: 10$ & $1: 10$ & \\
\hline $\begin{array}{l}\text { Escherichia coli } \\
\text { O157:H7 }\end{array}$ & $1: 40-1: 80$ & $1: 40$ & $1: 40-1: 80$ & $1: 40$ & $1: 320-1: 640$ & $1: 320$ & $1: 10$ & $1: 10$ & \\
\hline $\begin{array}{l}\text { Staphylococcus } \\
\text { aureus }\end{array}$ & $1: 80$ & $1: 80$ & $1: 80-1: 160$ & $1: 40$ & $1: 1280$ & $1: 640$ & $1: 20-1: 80$ & $1: 20$ & \\
\hline $\begin{array}{l}\text { Salmonella } \\
\text { Typhimurium }\end{array}$ & $1: 40$ & $1: 40$ & $1: 20-1: 40$ & $1: 10$ & $1: 160$ & $1: 320$ & $1: 10$ & $1: 10$ & \\
\hline $\begin{array}{l}\text { Salmonella } \\
\text { Enteritidis }\end{array}$ & $1: 40$ & $1: 40$ & $1: 20$ & $1: 20$ & $1: 320-1: 640$ & $1: 320$ & $1: 10$ & $1: 10$ & \\
\hline $\begin{array}{l}\text { Salmonella } \\
\text { Cholerasuis }\end{array}$ & $1: 40-1: 80$ & $1: 40$ & $1: 20$ & $1: 20$ & $1: 640$ & $1: 320$ & $1: 20$ & $1: 10$ & \\
\hline Bacillus cereus & $1: 160-1: 320$ & $1: 160$ & $1: 20-1: 40$ & $1: 10$ & $1: 320$ & $1: 160$ & $1: 20$ & $1: 20$ & \\
\hline Bacillus subtilis & $1: 80$ & $1: 80$ & $1: 80-1: 160$ & $1: 80$ & $1: 320$ & $1: 160$ & $1: 160-1: 320$ & $1: 80$ & \\
\hline $\begin{array}{l}\text { Pseudomonas } \\
\text { aeruginosa }\end{array}$ & $1: 40$ & $1: 20$ & 1:20-1:40 & $1: 10$ & $1: 320$ & $1: 320$ & $1: 10$ & $1: 10$ & \\
\hline Proteus mirabilis & $1: 40$ & $1: 40$ & $1: 20$ & $1: 20$ & $1: 640$ & $1: 640$ & $1: 20$ & $1: 10$ & \\
\hline
\end{tabular}

Para cada localidad, diferentes letras en el superíndice implican una diferencia significativa en el porcentaje de inhibición / For each location, different letters imply a significant difference in the percentage of inhibition.

Con respecto a la hoja de guayaba de San Pedro, su eficacia fue muy reducida, en general con todas las bacterias, en comparación con el aceite extraído de hojas de guayaba procedente de Escazú. El aceite obtenido en la localidad de San Pedro estuvo por completo inactivo con bacterias de los géneros Escherichia y Salmonella. Las hojas de Escazú, por su parte, mostraron porcentajes de inhibición entre 32,35\% y >100\%, con efectos de inhibición superiores incluso al control con antibiótico (Figuras 2 y 3 ). 

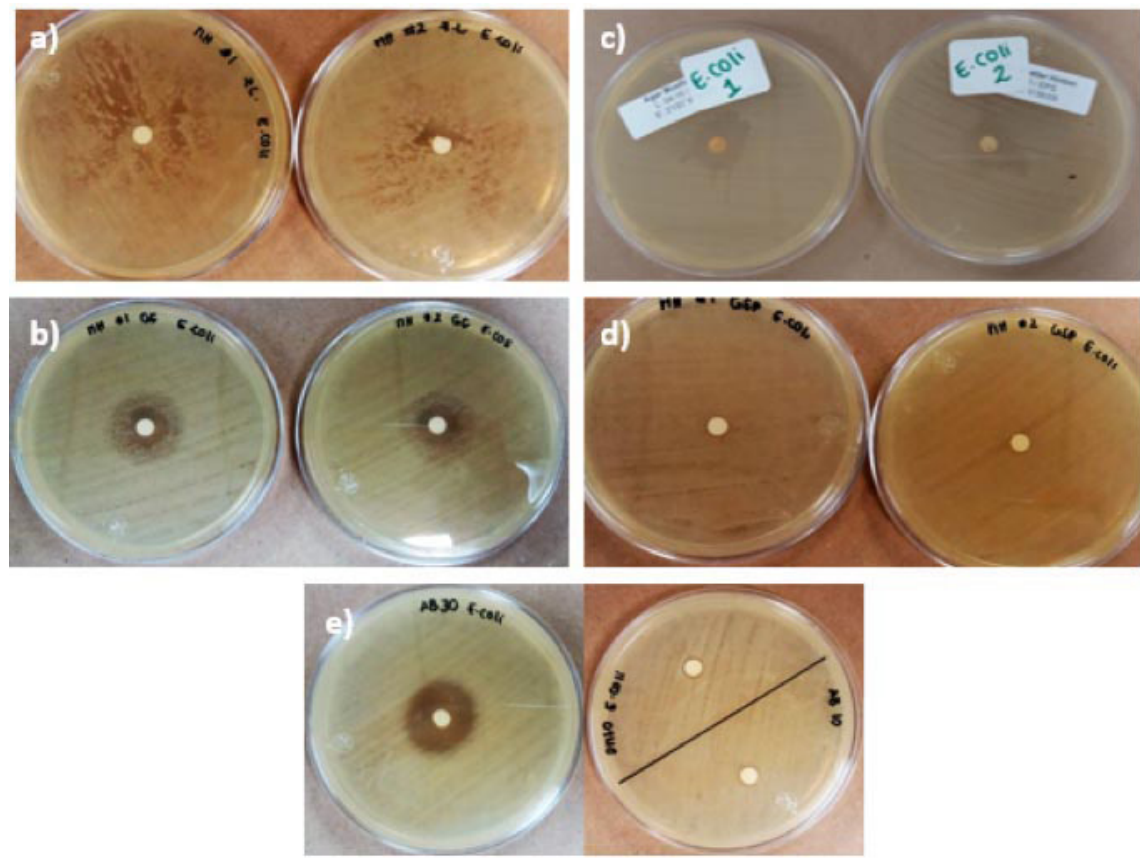

Figura 2. Pruebas de difusión con disco, a) zacate de limón Escazú, b) guayaba Escazú, c) zacate de limón Sarapiquí, d) guayaba San Pedro y e) control de antibiótico y dimetilsulfóxido (DMSO), en Escherichia coli. Centro de Investigación en Nutrición Animal (CINA), Universidad de Costa Rica. San José, Costa Rica. 2016.

Figure 2. Disc diffusion tests, a) Escazú lemongrass, b) Escazú guava leaf, c)Sarapiquí lemongrass, d) San Pedro guava leaf and e) Control of antibiotic and DMSO, in Escherichia coli. Centro de Investigación en Nutrición Animal (CINA), Universidad de Costa Rica. San José, Costa Rica. 2016.

\section{Determinación de la MIC y la MBC}

La inhibición del crecimiento microbiano por parte de los aceites esenciales en general, no generó la misma respuesta sobre todas las bacterias, esto se debe, principalmente, a las características propias de cada cepa bacteriana, la composición química de las plantas y la dosis de aceite que se utilice. Generalmente, las bacterias gram negativas presentaron mayor resistencia a los agentes antimicrobianos, con respecto a las MIC obtenidas.

El porcentaje de inhibición en tres de los cuatro extractos fue menor al 50\%. El extracto de acetona:agua, presentó porcentajes de inhibición mayores que los obtenidos con el aceite esencial de la misma planta muestreada en la localidad de Escazú (Cuadro 2 y 3 ).

Las hojas de guayaba de Escazú fueron el material vegetal que presentó los porcentajes de inhibición mayores, así como las MIC y MBC más bajas, esto quiere decir que logró ejercer un efecto bactericida a menores concentraciones que los otros aceites probados. Debido a esto, se seleccionó este material vegetal para preparar otros tres extractos botánicos con el empleo de acetona, etanol y metanol, respectivamente. 

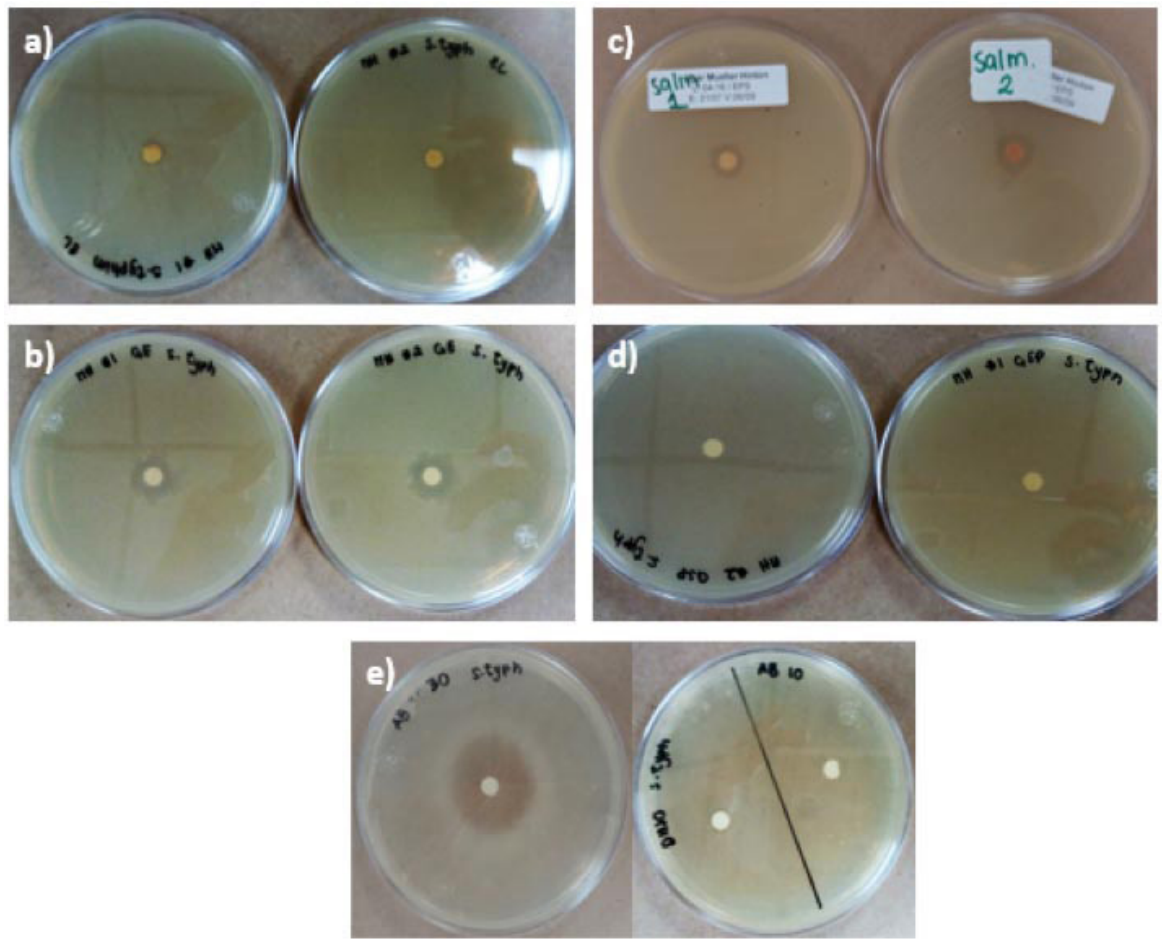

Figura 3. Pruebas de difusión con disco, a) Cymbopogon citratus Escazú, b) Psidium guajava Escazú, c) Cymbopogon citratus Sarapiquí, d) Psidium guajava San Pedro y e) control de antibiótico y dimetilsulfóxido (DMSO), en Salmonella enterica serovar Typhimurium. Centro de Investigación en Nutrición Animal (CINA), Universidad de Costa Rica. San José, Costa Rica. 2016.

Figure 3. Disc diffusion tests, a) Cymbopogon citratus Escazú, b) Psidium guajava leaf Escazú, c) Cymbopogon citratus Sarapiquí, d) Psidium guajava leaf San Pedro e) antibiotic control and DMSO, in Salmonella enterica serovar Typhimurium. Centro de Investigación en Nutrición Animal (CINA), Universidad de Costa Rica. San José, Costa Rica. 2016.

Cuadro 3. Determinación de actividad inhibitoria de cuatro extractos de hoja de guayaba (Psidium guajava) de Escazú, con base en el método de difusión en disco. Centro de Investigación en Nutrición Animal (CINA), Universidad de Costa Rica. San José, Costa Rica. 2016.

Table 3. Determination of inhibitory activity of four guava (Psidium guajava) leaf extracts from Escazú, using the disc diffusion method. Centro de Investigación en Nutrición Animal (CINA), Universidad de Costa Rica. San José, Costa Rica. 2016.

\begin{tabular}{lcccccccc}
\hline Microorganismo & \multicolumn{2}{c}{ Infusión } & \multicolumn{2}{c}{ Extracto Acetona:Agua } & \multicolumn{2}{c}{ Extracto etanólico } & \multicolumn{2}{c}{ Extracto metanólico } \\
\cline { 2 - 9 } & $\begin{array}{c}\text { Diámetro } \\
(\mathbf{m m})\end{array}$ & $\begin{array}{c}\text { Inhibición } \\
(\boldsymbol{\%})\end{array}$ & $\begin{array}{c}\text { Diámetro } \\
(\mathbf{m m})\end{array}$ & $\begin{array}{c}\text { Inhibición } \\
(\boldsymbol{\%})\end{array}$ & $\begin{array}{c}\text { Diámetro } \\
(\mathbf{m m})\end{array}$ & $\begin{array}{c}\text { Inhibición } \\
(\boldsymbol{\%})\end{array}$ & $\begin{array}{c}\text { Diámetro } \\
(\mathbf{m m})\end{array}$ & $\begin{array}{c}\text { Inhibición } \\
(\boldsymbol{\%})\end{array}$ \\
\hline $\begin{array}{l}\text { Escherichia coli } \\
\begin{array}{l}\text { Salmonella } \\
\text { Typhimurium }\end{array}\end{array}$ & 10 & 45,5 & 16 & 72,3 & 0 & 0 & 0 & 0 \\
\hline
\end{tabular}




\section{Ensayo en harina de carne y hueso}

En el análisis cualitativo de detección de Salmonella en la harina de carne y hueso se obtuvo presencia de la bacteria en ambos ensayos realizados, tanto en el tiempo 0 como 7 días luego de la inoculación (Cuadro 4). Con respecto a $E$. coli, el análisis fue cuantitativo. En el caso del ensayo 1 hubo un aumento en el número de bacterias en el transcurso de los siete días de ensayo. Sin embargo, en el ensayo 2 se observó una reducción del 100\% de la carga bacteriana inoculada (tiempo 0). Para corroborar el resultado del ensayo 2 se repitió, y se obtuvo nuevamente una reducción del $100 \%$ con respecto a la cantidad de E. coli en el tiempo 0 (Cuadro 4).

Cuadro 4. Evaluación del efecto antimicrobiano del aceite esencial de hojas de guayaba (Psidium guajava) de Escazú en harina de carne y hueso inoculada con Salmonella enterica serovar Typhimurium o Escherichia coli. Centro de Investigación en Nutrición Animal (CINA), Universidad de Costa Rica. San José, Costa Rica. 2016.

Table 4. Evaluation of the antimicrobial effect of the essential oil of guava (Psidium guajava) leaves from Escazú in meat and bone meal inoculated with Salmonella enterica serovar Typhimurium or Escherichia coli. Centro de Investigación en Nutrición Animal (CINA), Universidad de Costa Rica. San José, Costa Rica. 2016.

\begin{tabular}{cccc}
\hline & \multicolumn{3}{c}{ Salmonella enterica serovar Typhimurium } \\
\hline Periodo $(t$, días $)$ & Ensayo 1 & Ensayo 2 \\
0 & Presencia & Presencia & \\
7 & Presencia & Presencia \\
\hline & & Escherichia coli $(\mathbf{N M P} / \mathbf{g})$ & \\
\hline & Ensayo 1 & Ensayo $2\left(\mathrm{R}_{1}\right)$ & Ensayo $2\left(\mathrm{R}_{2}\right)$ \\
7 & $6,70 \times 10^{4}$ & $7,80 \times 10^{4}$ & $2,40 \times 10^{2}$ \\
& $>1,10 \times 10^{5}$ & $<3$ & $<3$ \\
\hline
\end{tabular}

\section{Discusión}

El proceso de extracción de aceites, se caracteriza por bajos porcentajes de recuperación, en el caso del zacate de limón, se reportó que la mayor cantidad de aceite (3\%) que se extrajo, con la hidrodestilación, a partir de hojas secas (Negrelle y Gomes, 2007), resultado superior a la recuperación obtenida en este estudio la cual fue de 0,33-0,43\% (Figura 1), por lo general, para zacate de limón se reportan entre 0,2 y 0,5\% (Shah et al., 2011), mientras que, la guayaba alcanza un rendimiento de extracción de $0,2 \%$ (Moura et al., 2012), muy similar al obtenido en esta investigación de 0,15-0,23\% (Figura 1). Varios factores del proceso de extracción, pudieron ser responsables de generar bajos rendimientos de recuperación de aceites esenciales; estos incluyen el método empleado, modificaciones al método de destilación, el cual, si por ejemplo, en lugar de sumergir el material en el agua, genera primero el vapor y este pase por el material vegetal, siendo el elemento que arrastra los componentes volátiles, podría mejorar la técnica para obtener mejores resultados (Guan et al., 2007). También el equipo utilizado en esta investigación (aparato general de hidrodestilación), pudo contribuir al porcentaje de recuperación de aceite obtenido en este estudio. Actualmente, existen equipos más industrializados que buscan obtener mayor cantidad de aceite esencial, entre ellos, destiladores que tienen una entrada para el arrastre de vapor, separador de aceites, o computadoras que analizan y monitorean el proceso de extracción (Schmidt, 2010). Adicionalmente, la 
falta de optimización de las condiciones del proceso, como, por ejemplo, la temperatura, la cantidad de agua, el tamaño de los trozos de material vegetal, el tiempo de destilación, entre otros, podrían disminuir los porcentajes de recuperación de los aceites esenciales (Cerpa, 2007). Los rendimientos de extracción de aceites menores al 1\% obtenidos en esta investigación, fueron el mayor factor limitante para realizar pruebas más específicas de capacidad antimicrobiana e incluir otras matrices alimentarias.

Las diferencias encontradas en composición química de los aceites esenciales y la concentración de sus componentes, puede deberse a que se evaluó material procedente de dos localidades para cada planta, las cuales presentan variaciones en sus condiciones climáticas, geográficas y de suelo, que se consideran factores que, según de-Souza et al. (2011) y Sonker et al. (2014), influyen en la constitución de los aceites, incluso en plantas de la misma especie.

El citral, es el componente en mayor concentración en el aceite de zacate de limón (70-80\%) (Negrelle y Gomes, 2007). Esto concuerda con los resultados obtenidos en esta investigación donde el $\alpha$ y $\beta$ citral corresponden al 80,28\% de los compuestos del aceite esencial de zacate de limón procedente de Escazú, y el 70,52\% del aceite procedente de Sarapiquí (Cuadro 1). La importancia de este abundante compuesto es que se le adjudican las propiedades antimicrobianas de la planta (Zulfa et al., 2016). Otro compuesto importante en el zacate de limón, es el mirceno, el cual es un monoterpeno, cuya función es reforzar el efecto antimicrobiano del citral (Negrelle y Gomes, 2007). En los resultados obtenidos, el mirceno se encontró en bajas concentraciones en el zacate de limón procedente de Escazú, se presentó como compuesto traza, ya que correspondió a menos del 1\%, mientras que, en el aceite de Sarapiquí, la concentración fue de 9,18\% (Cuadro 1). En una investigación anterior se demostró que el mirceno por sí solo tiene muy bajo efecto antimicrobiano en las bacterias probadas (Granados-Chinchilla et al., 2016).

Con respecto a los compuestos del aceite de la hoja de guayaba, la mayoría corresponden a sesquiterpenos, sin embargo, Nazzaro et al. (2013) indicaron que muchos de estos compuestos, pertenecientes a los terpenos, poseen poca o ninguna actividad antimicrobiana, tal es el caso del limoneno, cuya actividad es escasa, este se encontró en concentraciones de aproximadamente 3\% para ambas localidades probadas (Cuadro 2). En la investigación de Granados-Chinchilla et al. (2016), se comprobó la poca actividad antibacteriana de este compuesto. Autores como Arima y Danno (2002) sugirieron que la hoja de guayaba presenta buena actividad antimicrobiana, y que se debe a compuestos pertenecientes al grupo de los flavonoides.

A compuestos como el cariofileno y el óxido de cariofileno, se les atribuye la responsabilidad de la propiedad antioxidante en la guayaba (Roy et al., 2006). El cariofileno ha mostrado poca capacidad antimicrobiana tanto contra bacterias gram positivas como gram negativas (Granados-Chinchilla et al., 2016). El compuesto 2,4-ditert-butilfenol se encontró en mayor porcentaje 30,56\% en el aceite esencial de guayaba proveniente de Escazú en comparación con proveniente de San Pedro con un 7\% (Cuadro 1), a este compuesto se le ha atribuido capacidad antimicrobiana en otras investigaciones (Padmavathi et al., 2015; Varsha et al., 2015). La presentación 2,4-di-tertbutilfenol en mayor proporción en el aceite de guayaba proveniente de Escazú (30,56\%) podría ser una de las razones de que este aceite haya mostrado una mayor actividad antimicrobiana que el proveniente de San Pedro (7,53\%) (Cuadro 1).

En general, en las pruebas de actividad antimicrobiana, los aceites esenciales probados, presentaron un mayor efecto antibacterial ante bacterias gram positivas (Cuadro 2). Esto se debe, según Nazzaro et al. (2013) y Fernandes et al. (2014), a que la pared de las bacterias gram positivas consta de $90-95 \%$ de peptidoglicano, por lo que es sencilla la penetración de moléculas hidrofóbicas, mientras que, las bacterias gram negativas, tienen una capa delgada de peptidoglicano y una capa externa de lipopolisacáridos, además, entre ambas poseen enzimas capaces de inactivar moléculas desde fuera de la célula bacteriana. Lo anterior, se observó en la prueba de difusión por disco, donde géneros como Bacillus y Staphylococcus, que corresponden a gram positivos, presentaron porcentajes de inhibición bacteriana de 17 y $18 \%$ con el aceite de hoja de guayaba procedente de San Pedro, que en general tuvo un rendimiento de inhibición de 0 a $9 \%$ en las bacterias gram negativas evaluadas (Cuadro 2). 
En el caso de los extractos botánicos preparados a partir de las hojas de guayaba de Escazú, el extracto con acetona presentó la mayor actividad antibacteriana (Cuadro 3), lo cual podría deberse a la capacidad de la acetona de disolver componentes tanto hidrofílicos como lipofílicos (Eloff, 1998), tal es el caso de los polifenoles, que presentan una importante actividad antioxidante y antimicrobiana, y se encuentran presentes en la guayaba (Zapata et al., 2013).

El resultado obtenido con los extractos metanólicos y etanólicos, que no presentaron efecto inhibitorio, no fueron acorde a lo reportado en la literatura, ya que Biswas et al. (2013) e Ifeanyichukwu et al. (2015), indicaron que los extractos de hoja de guayaba, con estos mismos disolventes, presentan una notable actividad inhibitoria contra algunas bacterias gram positivas y gram negativas. La elección del aceite esencial de hoja de guayaba procedente de Escazú, para realizar pruebas en harina de carne y hueso, se debió a que presentó buenos resultados en la prueba de difusión en disco y las menores MIC (Cuadro 2), lo que coincide con lo expuesto por de-Souza et al. (2011), que indicaron que el aceite de guayaba presenta una importante actividad bactericida a bajas concentraciones. Una MIC baja presenta importantes ventajas, basándose en la dificultad de obtener los aceites esenciales por los bajos rendimientos de extracción.

El aceite de guayaba presenta varios compuestos de la familia de terpenos y flavonoides con una fuerte acción antibacteriana (Pérez et al., 2008), los cuales, en conjunto, podrían ser más eficientes que la acción del citral y mirceno del zacate de limón, que con base en los resultados obtenidos (Cuadros 2), se puede concluir que tienen una importante actividad antimicrobiana.

Los ensayos de aceite esencial de guayaba proveniente de Escazú realizados en una matriz de harina de carne y hueso no presentaron la actividad antibacteriana esperada contra Salmonella. Esta baja eficiencia del aceite en la harina se pudo deber a la limitación del efecto antibacteriano de los componentes del aceite, causado por las estructuras físicas de los alimentos, como sus componentes y su pH, o por factores extrínsecos como la temperatura, o las características de los microorganismos (Perricone et al., 2015).

La harina de carne y hueso, la cual se usa como materia prima para la elaboración de alimentos para animales productivos monogástricos y para perros, presenta una importante cantidad de proteína $(45,9 \%)$ y de grasa $(18,2 \%)$ (Leiva et al., 2018). Las altas concentraciones esos nutrientes en matrices de alimentos, indica que pueden generar un efecto de protección en las bacterias a nivel de membrana y mediante la absorción del aceite esencial (Perricone et al., 2015). En tales casos, se ha reportado que es necesario aplicar una concentración de aceite mayor a la MIC obtenida en los ensayos in vitro (Fischer y Phillips, 2008). En esta investigación además, la consistencia grasosa de la harina de carne y hueso, dificultó la aplicación del aceite y la distribución homogénea del mismo.

La prueba para determinar Salmonella spp., corresponde a una prueba cualitativa de presencia o ausencia, por lo que, los resultados obtenidos (Cuadro 4) no dan la información suficiente para indicar si el aceite presentó capacidad inhibitoria, ya que no se determinó la concentración de bacterias en el transcurso del tiempo. Se indica que el aceite esencial disminuye la cantidad de Salmonella Typhimurium en ingredientes para piensos (Burt, 2004; Cochrane et al., 2016), sin embargo, esa disminución puede variar dependiendo de la matriz analizada.

En el caso de Escherichia (Cuadro 4), el aceite esencial de hoja de guayaba en el ensayo \# 2 presentó un 100\% de capacidad antimicrobiana en contraste con el mismo aceite en el ensayo 1, esto podría deberse a la inactivación del aceite por los diferentes componentes del alimento, al estar primero una hora en el alimento antes de entrar en contacto con las bacterias. Sin embargo, otros autores han demostrado la efectividad de los aceites esenciales de otras plantas, en la conservación de formulaciones proteicas y cárnicas y la inhibición o control de E. coli en ingredientes similares a la harina de carne y hueso (Arellano y Montesdeoca, 2016). 


\section{Conclusiones}

Los aceites esenciales extraídos a partir de zacate de Limón cultivado en las localidades de Escazú y Sarapiquí, así como el aceite esencial extraído de hojas de guayaba provenientes de Escazú, presentaron actividad microbiana contra bacterias gram postivas y gram negativas. En el caso del zacate de Limón esta capacidad antimicrobiana es posiblemente debida a la alta concentración (70-80\%) de $\alpha$ y $\beta$ citral encontrados en esta investigación y que ya se ha descrito que poseen efecto antimicrobiano. En el caso del aceite esencial de hojas de guayaba, la capacidad antibacteriana que se presentó en el cultivo de Escazú puede deberse en parte al compuesto 2,4-di-tert-butilfenol; una evidencia de esta hipótesis es la poca o nula actividad antimicrobiana encontrada en las hojas de guayaba cultivadas en San Pedro, las cuales presentaron una menor concentración de este compuesto.

El aceite esencial de hoja de guayaba de Escazú mostró ser efectiva al disminuir la concentración de Escherichia coli en harina de carne hueso, la cual es una materia prima frecuentemente usada en la elaboración de alimentos para perros, aves y cerdos. Sin embargo los efectos de este aceite esencial en harina de carne y hueso contaminada con Salmonella no fueron concluyentes.

Según los resultados obtenidos en esta investigación los aceites esenciales de zacate de Limón y de hoja de guayaba cultivadas en Costa Rica, podrían presentar un efecto antimicrobiano contra bacterias relevantes para la inocuidad y la vida útil de harina de carne y hueso usada en alimentación animal. Se requiere futuras investigaciones con mayor número de repeticiones, con mayor variedad de alimentos para animales y que además incluyan pruebas en animales, en donde se tomen en cuenta pruebas como palatibilidad, rendimientos productivos, entre otros, para evaluar la aplicabilidad del uso de estos extractos botánicos como alternativa al uso de antibióticos en alimentación animal. La futura implementación de extractos botánicos producidos en el país como alternativa al uso de antibióticos en alimentación animal es de alta relevancia comercial y de salud pública.

\section{Literatura citada}

Arellano, A.R., y F.P. Montesdeoca. 2016. Evaluación de preservantes naturales, para incrementar el tiempo de vida útil de análogos proteicos elaborados con Quinua. Tesis Ing., Universidad de las Américas, Quito, ECU.

Arima, H., and G.I. Danno. 2002. Isolation of antimicrobial compounds from guava (Psidium guajava L.) and their structural elucidation. Biosci. Biotechnol. Biochem. 66:1727-1730. doi:10.1271/bbb.66.1727

Bakkali, F., S. Averbeck, D. Averbeck, and M. Idaomar. 2008. Biological effects of essential oils - A review. Food Chem. Toxicol. 46:446-475. doi:10.1016/j.fct.2007.09.106

Balouiri, M., M. Sadiki, and S.K. Ibnsouda. 2016. Methods for in vitro evaluating antimicrobial activity: A review. J. Pharma. Anal. 6(2):71-79. doi:10.1016/j.jpha.2015.11.005

Bassolé, I.H., and H.R. Juliani, 2012. Essential oils in combination and their antimicrobial properties. Molecules 17:3989-4006. doi: $10.3390 /$ molecules 17043989

Biswas, B., K. Rogers, F. McLaughlin, D. Daniels, and A. Yadav. 2013. Antimicrobial activities of leaf extracts of guava (Psidium guajava L.) on two gram-negative and gram-positive bacteria. Int. J. Microbiol. 2013:ID746165. doi:10.1155/2013/746165

Boire, N.A., S. Riedel, and N.M. Parrish. 2013. Essential oils and future antibiotics: new weapons against emerging 'superbugs'? J. Anc. Dis. Prev. Rem. 1:105. doi:10.4172/2329-8731.1000105

Burt, S. 2004. Essential oils: their antibacterial properties and potential applications in foods - A review. Int. J. Food Microbiol. 94:223-253. doi:10.1016/j.ijfoodmicro.2004.03.022

Agron. Mesoam. 30(1):147-163, enero-abril, 2019

161

ISSN 2215-3608 doi:10.15517/am.v30i1.33758 
Cerpa, M.G. 2007. Hidrodestilación de aceites esenciales: Modelado y caracterización. Tesis Dr., Universidad de Valladolid, Valladolid, ESP. http://www.anipam.es/downloads/43/hidrodestilacion-de-aceites-esenciales.pdf (consultado 23 de Abril del 2018).

CLSI (Clinical and Laboratory Standards Institute). 2012. Methods for dilution antimicrobial susceptibility test for bacteria that grow aerobically; approved standard. $9^{\text {th }}$ ed. CLSI, PA, USA.

Cochrane, R.A., A.R. Huss, G.C. Aldrich, C.R. Stark, and C.K. Jones. 2016. Evaluating chemical mitigation of Salmonella Typhimurium ATCC 14028 in animal feed ingredients. J. Food Prot. 79:672-676. doi:10.4315/0362-028X.JFP-15-320

de-Souza, L., L.F. Damé, G. Hörnke, M.A. Ziemann, M.R. Alves, y M.C. Araújo. 2011. Evaluación de la actividad bactericida de aceites esenciales de hojas de guayabo, pitango y arazá. Rev. Cubana Plant. Med. 16:324-330.

Eloff, J.N. 1998. Which extractant should be used for the screening and isolation of antimicrobial components from plants? J. Ethnopharmacol. 60:1-8. doi:10.1016/S0378-8741(97)00123-2

Fernandes, M.R.V., A.L.T. Dias, R.R. Carvalho, C.R.F. Souza, and W.P. Oliveira. 2014. Antioxidant and antimicrobial activities of Psidium guajava L. spray dried extracts. Indust. Crops Prod. 60:39-44. doi:10.1016/j.indcrop.2014.05.049

Fischer, K., and C. Phillips. 2008. Potential antimicrobial uses of essential oils in food: is citrus the answer? Trends Food Sci. Technol. 19:156-164. doi:10.1016/j.tifs.2007.11.006

Granados-Chinchilla, F. 2017. A review on phytochemicals (including essential oils and extracts) inclusion in feed and their effects on food producing animals. Dairy Vet. Sci. J. 3(4):555620. doi:10.19080/JDVS.2017.03.555620

Granados-Chinchilla, F., E. Villegas, A. Molina, and C. Arias. 2016. Composition, chemical fingerprinting and antimicrobial assessment of Costa Rican cultivated guavas (Psidium friedrichsthalianum (O. Berg) Nied. and Psidium guajava L.) essential oils from leaves and fruits. Nat. Prod. Chem. Res. 4:236. doi:10.4172/2329-6836.1000236

Guan, W., S. Li, R. Yan, S. Tang, and C. Quan. 2007. Comparison of essential oils of clove buds extracted with supercritical carbon dioxide and other three traditional extraction methods. Food Chem. 101:1558-1564. doi:10.1016/j.foodchem.2006.04.009

Ifeanyichukwu, I., E. Chika, N. Emmanuel, O. Anthonia, A. Ngozi, and N. Agabus. 2015. Preliminary investigation of the antibacterial activity of Psidium guajava extracts. Eur. J. Med. Plants 7:26-30. doi:10.9734/EJMP/2015/14307

Jahani, S., S. Saeidi, F. Javadian, Z. Akbarizadeh, and A. Sobhanizade. 2016. Investigating the antibacterial effects of plant extracts on Pseudomonas aeruginosa and Escherichia coli. Int. J. Infect. 3(2):e34081 doi:10.17795/iji-34081

Jorgensen, J.H., and M.J. Ferraro. 2009. Antimicrobial susceptibility testing: a review of general principles and contemporary practices. Clin. Infect. Dis. 49:1749-1755. doi:10.1086/647952

Joseph, B., and R.M. Priya. 2011. Phytochemical and biopharmaceutical aspects of Psidium guajava (L.) essential oil: A review. Res. J. Med. Plants 5432-442 doi:10.3923/rjmp.2011.432.442

Leiva, A., F. Granados-Chinchilla, M. Redondo-Solano, M. Arrieta-González, E. Pineda-Salazar, and A. Molina. 2018. Characterization of the animal by-product meal industry in Costa Rica: Manufacturing practices through the production chain and food safety. Poult. Sci. 97:2159-2169 doi:10.3382/ps/pey058

Martínez, M.J., N. Molina, y E. Boucourt. 1997. Evaluación de la actividad antimicrobiana del Psidium guajava L. (Guayaba). Rev. Cubana Plant. Med. 2:12-14.

Molina, A., F. Granados-Chinchilla, M. Jiménez, M. Acuña-Calvo, M. Alfaro, and G. Chavarría. 2016. Vigilance for Salmonella in feedstuffs available in Costa Rica: prevalence, serotyping and tetracycline resistance of isolates obtained from 2009 to 2014. Foodborne Pathog. Dis. 13(3):119-127. doi:10.1089/fpd.2015.2050 
Moura, P.M., G.H.C.Prado, M.A.A. Meireles, and C.G.Pereira. 2012. Supercritical fluid extraction from guava (Psidium guajava) leaves: global yield, composition and kinetic data. J. Supercrit. Fluid. 62:116-122. doi:10.1016/j.supflu.2011.11.04

Nazzaro, F., F. Fratianni, L. De-Martino, R. Coppola, and V. De-Feo. 2013. Effect of essential oils on pathogenic bacteria. Pharmaceuticals 6:1451-1474. doi:10.3390/ph612145

Negrelle, R.R.B., and E.C. Gomes, E.C. 2007. Cymbopogon citratus (DC.) Stapf: chemical composition and biological activities. Rev. Bras. Plantas Med. 9(1):80-92.

Padmavathi, A.R., D. Bakkiyaraj, N. Thajuddin, and S.K. Pandian. 2015. Effect of 2, 4-di-tert-butylphenol on growth and biofilm formation by an opportunistic fungus Candida albicans. Biofouling 31:565-574. doi:10.1080/08927014.2015.1 077383

Pérez, R.M., S. Mitchell, and R.V. Solis. 2008. Psidium guajava: a review of its traditional uses, phytochemistry and pharmacology. J. Ethnopharmacol. 117:1-27. doi:10.1016/j.jep.2008.01.025

Perricone, M., E. Arace, M.R. Corbo, M. Sinigaglia, and A. Bevilacqua. 2015. Bioactivity of essential oils: a review on their interaction with food components. Front. Microbiol. 6:76 doi:10.3389/fmicb.2015.00076

Rivera, J., P.G. Crandall, C.A. O’Bryan, and S.C. Ricke. 2015. Essential oils as antimicrobials in food systems: A review. Food Control 54:111-119. doi:10.1016/j.foodcont.2014.12.040

Roy, C.K., J.V. Kamath, and M. Asad. 2006. Hepatoprotective activity of Psidium guajava Linn. leaf extract. Indian J. Exp. Biol. 44:305-311.

Schmidt, E. 2010. Production of essential oils. En: K.H.C. Baser, and G. Buchbauer, editors, Handbook of essential oils: science, technology, and applications. Taylor \& Francis Group, FL, USA. p. 83-120.

Shah, G., R. Shri, V. Panchal, N. Sharma, B. Singh, and A.S. Mann. 2011. Scientific basis for the therapeutic use of Cymbopogon citratus, stapf (Lemon grass). J. Adv. Pharm. Technol. Res. 2:3-8. doi:10.4103/2231-4040.79796

Sonker, N., A.K. Pandey, P. Singh, and N.N. Tripathi. 2014. Assessment of Cymbopogon citratus (DC.) stapf essential oil as herbal preservatives based on antifungal, antiaflatoxin, and antiochratoxin activities and in vivo efficacy during storage. J. Food Sci. 79:628-634. doi:10.1111/1750-3841.12390

Varsha, K.K, L. Devendra, G. Shilpa, S. Priya, A. Pandey, and K.M. Nampoothiri. 2015. 2,4-Di-tert-butyl phenol as the antifungal, antioxidant bioactive purified from a newly isolated Lactococcus sp. Int. J. Food Microbiol. 211:44-50. doi:10.1016/j.ijfoodmicro.2015.06.025

Zapata, K., F.B. Cortes, y B.A. Rojano. 2013. Polifenoles y actividad antioxidante del fruto de Guayaba Agria (Psidium araca). Inf. Tecnol. 24(5):103-112. doi:10.4067/S0718-07642013000500012

Zulfa, Z., C.T. Chia, and Y. Rukayadi. 2016. In vitro antimicrobial activity of Cymbopogon citratus (lemongrass) extracts against selected foodborne pathogens. Int. Food Res. J. 23:1262-1267. 